\title{
Breve recuento de \\ la modernización de la \\ política turística mexicana
}

DOI: 10.22403/UQROOMX/TYP03/01

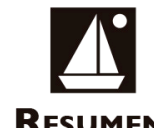

$$
\begin{aligned}
& \text { Marcelino Castillo Néchar* } \\
& \text { Elva Esther Vargas Martínez }
\end{aligned}
$$

La importancia que cobra la modernización de la política turística va más allá de la bonanza y el beneficio que enarbola el discurso oficial de las grandes corporaciones y organismos internacionales de financiamiento; implica reconocer la existencia de un modelo de conducción llamado industria turística, que encubre las situaciones del poder real, el papel de las instituciones y sus reformas, así como el rol que juega el Estado ante la globalización y el auge del mercado.

Palabras | Estado, globalización, modernización, política, turismo.

CLAVE

*Universidad Autónoma del Estado de México / mercanec62@hotmail.com

** Universidad Autónoma del Estado de México / elvacolegio@hotmail.com 


\section{Introducción}

Como nunca antes, en los últimos años el mundo ha estado más sujeto a los procesos de globalización y entrelazamiento de las economías nacionales en el ámbito económico, político, financiero, sociocultural y educativo.A la luz de estos procesos ha aumentado significativamente la importancia del turismo como una actividad económica, sobre todo para los países en vías de desarrollo, que generalmente presentan balanzas comerciales regularmente deficitarias. En este sentido, el discurso oficial establece la importancia del turismo por su capacidad para generar divisas, empleos y desarrollo regional; imprescindibles en la modernización del sector.

Empero, bajo la idea de modernización del turismo, el país ha transitado de un periodo a otro por modelos que evidencian la crisis generalizada de lo económico y lo social y, con ello, el turismo y sus políticas se han visto influidos no sólo por la ideología imperante sino por los mecanismos y principios caducos para operarlo y evaluarlo.

Hoy, la política turística de modernización requiere de una reflexión profunda sobre los significados del turismo, sus impactos en la vida económica, social, cultural y ambiental del país, más allá de su tratamiento como simple acción general y refuncionalizadora de los viejos principios de la industria turística por los de competitividad, productividad y posicionamiento en el contexto de la globalización y el neoliberalismo, pues ello sólo está significando instrumentalizar la razón de la modernización turística que equipara progreso y crecimiento con desarrollo.

\section{La concepción tradicional de la política y sus tendencias}

Existe una gran cantidad de definiciones de política turística en su proceso de modernización. Algunas desde la perspectiva de los desplazamientos (OMT, 2002:7); otras, desde la planificación democrática (Ortuño, 1966:208), así como aquellas que desde la economía destacan los aspectos físico-espaciales y de recursos (Monfort, 2000: 7-27), entre otras. Sin embargo, podemos agruparlas -grosso modo- en dos: las de la perspectiva tradicional y las de la corriente alternativa, esta última elabora su análisis desde la política regional (Molina, 1985: 100-106). 
Lo relevante de tales enfoques es que sus argumentos van desde la descripción de las manifestaciones visibles de la política turística para configurarla como una importante fuerza económica, hasta aquellos que la ubican en la crítica de modelos preestablecidos de la economía dependentista; además, mientras que algunas la conceptúan desde una visión social, antropológica y cultural, con variaciones que comprenden la cuestión desinteresada y humanista del juego y el placer, otras la proponen como un medio para el colonialismo cultural y el conflicto de intereses. Sin embargo, lo que ahora interesa es señalar que -en general- al turismo se le ve como un hecho al que se le "aplican" políticas (léase: acciones) para su conducción, ejecución y evaluación con variaciones de "concepción" y operatividad, según el momento histórico y los gobiernos en turno, pero sin un análisis ideológico de eso llamado modernización, que encubre más de lo que en realidad muestra.

Por ejemplo, una definición clásica de la política turística es la que la señala como un "conjunto de actitudes y estrategias que una colectividad organizada adopta ante el fenómeno turístico. Asimismo, la política turística es producto de la política general de un Estado y estará supeditada siempre a razones de orden público" (De la Torre, 1982:23). En torno a esta idea se asume que una política del turismo debe responder a los intereses cada vez más crecientes en el plano económico y social que generan los movimientos de personas y que repercuten en la balanza de pagos de los países, la cuestión laboral, la preservación del patrimonio nacional, etc., que no puede escapar a la tensión de los gobiernos. En cuanto a esto, se indica que:

La evaluación de la actividad oficial respecto del turismo ha seguido la línea de la evolución general de las teorías y de las prácticas administrativas del Estado moderno. Mientras la administración tiene un estricto carácter de guardián del orden económico, su preocupación consiste en hacer que se cumplan las formas establecidas y vigilar el juego limpio entre las partes interesadas, en el cuadro de un mercado de competencia libre [Ortuño, 1966: 203-204].

Hoy, sin embargo, ese manejo -supuestamente político del turismo- ha sido relegado por lo económico, condicionando lo político como función principal del Estado al aspecto anterior.

Es cierto, en materia de políticas públicas turísticas hablamos de cursos de acción propuestos por los organismos de gobierno y los servidores públicos 
para resolver problemas en la materia que les concierne, pero el llevar a cabo este curso de acción requiere la participación de un algo conocido como sector que involucra, no sólo a un organismo técnico y administrativo, sino también a prestadores de servicios, usuarios, población, medios, estructuras, intelectuales de la materia, recursos, etc., aunque hoy la modernización de la acción política rebasa estos elementos locales para involucrar a agentes externos internacionales.

Es por ello que cuando se alude al papel modernizador del Estado -como administrador público- se le relaciona con sus actividades de planeación, organización, control y vigilancia para alcanzar los objetivos señalados, así como de las relaciones sociales y la normatividad que protege el "interés común”; aunque aquí es conveniente preguntar ¿de qué interés común se está hablando?

La respuesta podría darla la propia concepción tradicional de administración pública, conforme a la cual el Estado funge de manera paternalista al "afirmar e incrementar su poder y hacer buen uso de sus fuerzas, procurar la felicidad de sus súbditos [...] atendiendo a que la felicidad del Estado depende de la inteligencia con que todas las cosas son administradas" (Guerrero, 1986: 12).

Aquí, la política, derivada del término policía, adquiere un significado más amplio referido a "un complejo conjunto de acciones técnicas y procesos preventivos, estimulantes, correctivos, organizativos y represivos, encaminados a fortalecer al Estado vía la nutrición material, moral e intelectual de la sociedad civil" (Guerrero, 1986: 225).

Pero este tipo de política, en un Estado paternalista, populista y bonapartista, que se basa en una aparente economía fuerte y sana para el beneficio de la sociedad, no es sino reflejo y consecuencia del estado social y sociabilidad natural del hombre; su naturaleza es un resultado de la comunidad, pues desde que existe un pacto social hay administración. Así, siempre se encuentra esa naturaleza, hasta en el despotismo. Es, pues, evidente que la administración no toma sus principios de convenios humanos, sino que es un fenómeno de la existencia misma de la sociedad y sus convenios o leyes únicamente sirven para organizarla, es decir, para determinar su modo de existir. En el mismo Estado liberal, explicado por Tocqueville (1957: 137), tales beneficios a la sociedad también son palpables, pero con otro significado: permitir que el mercado regule las relaciones entre particulares, donde los supuestos racionalistas e 
individualistas imperan, trastocando los valores y haciendo que las personas se individualicen por los intereses muy particulares que emergen.

En aquella concepción tradicional, a la modernización de la política pública del turismo se le vincula con la llamada política turística, entendida como:"la acción del Estado integrada por una serie de disposiciones destinadas a regular, fomentar y proteger las actividades turísticas" (Novo, 1977: 200).

Por otro lado, cabe indicar la orientación con la que se manifiesta el discurso político en materia de turismo en México: con un matiz social, cuando se alude a la práctica interna; respetuoso y rescatador de nuestros valores tradicionales, cuando se dirige a las comunidades étnicas; nacionalista, cuando se quiere hacer notar la importancia de los micro y pequeños empresarios; modernista y altamente competitivo, cuando se quiere referir a la inversión extranjera. Empero, el trasfondo está permeado por la valoración económica y de rendimiento para atraer y fomentar la reproducción del gran capital.

En suma, se puede decir que:

la política del desarrollo turístico que ha seguido el Estado mexicano se enmarca dentro de una política general de planeación para el desarrollo que intenta aminorar ciertas contradicciones inherentes al sistema, así como apoyar a la iniciativa privada al pretender, entre otras cosas, el desarrollo industrial y agrícola, la generación de empleos, la redistribución del ingreso y nivelar la desigualdad regional [García de Fuentes, 1979: 20].

Sin que a pesar de ello muchas de estas cosas las haya logrado.

Entre los clásicos del turismo, la concepción que se tiene de modernización política turística transita desde la interayuda profesional, la propaganda, el proteccionismo y la adaptación, hasta la fase de planificación (Moreno, 1969; Torruco, 1988; Herrerías, 1958; MacDonald, I98I; Romero, I977; Jiménez, 1992).

\section{EI criterio político de la modernización:} la planeación democrática

En México, el criterio político de modernización para el turismo ha girado en torno a lo que se conoce como planeación democrática. Desde 1983 se instaura y consolida un sistema nacional de planeación democrática como un compromiso indeclinable del Ejecutivo para la conducción, orden y racionalidad 
del esfuerzo colectivo, en cumplimiento del Proyecto Nacional (Secretaría de la Presidencia, 1983: 37). Sin embargo, previo al rimbombante nombre de planea-ción democrática ya había antecedentes de una planeación oficial. Entre 1917 y 1946, la Revolución da pauta a un proyecto nacional de ordenamiento, manifiesto en principios fundamentales como el sistema federal, la división de poderes, la no reelección, los derechos individuales $y$, en esencia, los artículos $3^{\circ}, 27$ y 123 , que colocan a México como el primero en garantizar los derechos sociales (Secretaría de la Presidencia, 1983: 94).

Si la década de los treinta se caracterizó por experimentos de política económica destinados a superar la situación creada por la crisis internacional de 1929 (Sunkel, 1976: 229), el periodo 1940-1946 continuaba con la línea: consolidar la reforma agraria, la cual constituía su principal objetivo; aunque también se definen otros conceptos referentes a la planeación y al papel del Estado en el proceso de desarrollo; se recalca la formación de capital -principalmente privado- y se destaca la necesidad de impulsar la formación de la infraestructura de comunicaciones y transportes.

En ese contexto, no es sino hasta el 24 de diciembre de 1958 cuando, con la Ley de Secretarías y Departamentos de Estado, se crea el Departamento de Turismo como un organismo autónomo, y hasta el 3I de diciembre de 1974 -por decreto publicado en el Diario de la Federación- adquiere el rango de Secretaría de Estado.

El turismo ha sido considerado en el Proyecto - de la Ley de Secretarías y Departamentos de Estado- como una actividad de especial importancia que requiere estímulo, promoción y fomento, debiendo destinarse a ello los recursos que le correspondan. De ahí que se haya juzgado pertinente crear un departamento específico, con facultades suficientes y medios adecuados para cumplir las funciones que le conciernen [Olivera, 1970: 23].

Cabe señalar que en $196 \mathrm{I}$ se crea la primera Ley Federal de Turismo compuesta por cinco títulos que en diferentes capítulos contienen la reglamentación de las siguientes materias: Disposiciones generales,Autoridades de turismo, Comisiones locales, Cámaras y confederaciones de cámaras de turismo, Organización nacional del turismo, Derechos y obligaciones de los prestadores de servicios turísticos, Catálogo turístico nacional, Fomento del turismo, Sanciones por incumplimiento de las normas que contiene la Ley y Transitorios (Diario Oficial de la Federación, 196I). 
Para unificar los criterios sobre planificación, hacia 1963, el Senado de la República -a través de una Comisión de Planeación- elabora el Proyecto de Ley Federal de Planeación. En éste predominaba el concepto de planeación como proceso que al mediano y largo plazos encauzarían la modernización y el desarrollo económico del país, satisfaciendo las necesidades de la población.

Este plan de acción inmediata se formuló ante al virtual estancamiento de la economía nacional. El Plan de Desarrollo Económico y Social tenía una visión más global con respecto al desarrollo equilibrado y a la mejora de vida de la población. La política proteccionista del país, con el fin de estimular la inversión nacional, estableció una serie de condiciones para limitar la inversión extranjera; el presidente Echeverría afirmaba que la inversión extranjera no debía desplazar al capital mexicano, sino complementarlo, asociándose a él cuando fuera útil; y el capital mexicano, en todo caso, dirigir el encuentro con sagacidad, señorío y patriotismo, y encauzarlo para modernizar las empresas (Tello, 1983: 58).

En el turismo, esta política proteccionista dejaba ver ciertos avances económicos y una relativa apertura a la entrada de productos, actividades comerciales, financieras y de servicios; mostraba el creciente gasto del turismo nacional en el extranjero y gestaba la idea y signos del progreso.Así, el periodo 1958-1970 se caracterizó por un acelerado crecimiento y diversificación del aparato productivo, a lo cual se sumó la creación de parques y ciudades industriales con la intención de promover el desarrollo regional. Empero, la escasa difusión de las actividades de planeación dieron como resultado una escasa participación de la sociedad en la elaboración y ejecución de los planes.

En cuanto al periodo 1970-1976, su característica principal fue un contexto internacional difícil. La decisión de los Estados Unidos de abandonar la convertibilidad de su moneda en oro generó desajustes en el sistema monetario internacional, lo cual afectó agudamente a México al disminuir sus exportaciones y aumentar los precios de sus importaciones. Por ello se formuló una nueva estrategia de desarrollo llamada estabilizadora, la cual buscó incrementos cualitativos en la producción, adecuaciones políticas, económicas, culturales y organizativas para elevar el nivel de vida de la población.

Después de la crisis de 1976, se manifestó una cierta urgencia por articular en forma racional la instrumentación de políticas que coadyuvarían a 
la recuperación; de esta manera, se elabora el Plan Básico de Gobierno 19761982, que fue presentado por el Partido Revolucionario Institucional como plataforma electoral y constituyó el planteamiento político sobre los problemas económicos y sociales del país.

La política que siguió el quehacer turístico durante este periodo tuvo una fuerte influencia de la anterior, en el sentido de que sigue concibiendo al turismo como una alternativa importante para promover el desarrollo económico nacional, para generar empleos directos e indirectos, estimular otras actividades productivas, captar divisas y propiciar el desarrollo regional. Sin embargo, dado que aquél fue un periodo de crisis económica nacional, la política turística tendía más bien a desestimular el turismo egresivo y a promover el turismo receptivo e interno; es decir, se implantó una política turística enfocada hacia la demanda a fin de incrementar los ingresos nacionales, disminuir la salida de divisas y redistribuir la riqueza. La perspectiva económica de la política enfocada hacia el estímulo y aprovechamiento de la demanda fue apoyada por una política comercial tendiente a ampliar la venta del producto turístico nacional en el extranjero. Para ello, se promovió la afluencia a los centros de categoría elevada, localizados sobre todo en lugares de playa. Lo que se pretendía con esta política era incrementar el número de visitantes extranjeros, aumentar la captación de divisas, ampliar la ocupación de la planta e incrementar el consumo de los visitantes.

En relación con la oferta turística, se buscaba mejorar la infraestructura y los servicios turísticos en los centros turísticos tradicionales; además, ampliar la capacidad de la planta hotelera y la oferta de hospedaje, sobre todo en aquellos destinos dirigidos a satisfacer la demanda de la corriente extranjera. Como complemento al aumento de la planta, se pretendió también el mejoramiento en la prestación de los servicios, para lo cual se estableció como medida insoslayable el aumento de la capacitación al personal que se empleaba en el sector. Todo ello, con la firme intención de modernizar al sector turístico.

Bajo la idea de un desarrollo más equilibrado, y con la política del sector público de participar en la construcción de infraestructura para fomentar la inversión privada y la habilitación de la planta turística, se inició un proceso de construcción de infraestructura y planta turística en los llamados polos de desarrollo turístico; la justificación era que, dada su ubicación estratégica, se 
esperaba que contribuyeran al impulso del desarrollo regional al estimular las actividades productivas del entorno donde se ubicaran, y promover así un desarrollo más equilibrado. Lo cierto es que fue todo lo contrario. La política turística establecida para este periodo estuvo básicamente enfocada al aprovechamiento y beneficio de la demanda e inversión extranjeras, al desarrollo de la planta turística, al incremento de la capacidad de hospedaje y a la calidad en los servicios para el buen funcionamiento de la planta turística.

Para el periodo de 1980 a 1982 se elabora el Plan Global de Desarrollo, por decreto promulgado en el Diario Oficial de la Federación el 17 de abril de 1980, por medio del cual se establecen las acciones dentro de un marco estratégico general que contribuyó a homogeneizar la metodología, enfoques, procedimientos y conceptualización de la problemática relacionada con la planeación del desarrollo. El documento se integró de tres partes: una política, una económica y una social (SPP, 1980: 32).

Se consideró que la planeación para el desarrollo no debería agotarse en la formulación de planes, por lo cual se propuso la creación de un Sistema Nacional de Planeación que compatibilizara y coordinara los esfuerzos de la población y el gobierno hacia objetivos generales de desarrollo. Se pretendía hacer de este sistema de planeación una propuesta integradora, participativa y democrática. Así, la experiencia en materia de formulación de políticas turísticas se supeditó -hasta ese momento- a una acción planificadora para el desarrollo.

Cabe señalar que dada las condiciones de crisis del país en materia de desarrollo económico y social hacia 1980, el gobierno federal formula el Plan de Desarrollo con sus respectivos planes sectoriales, en el cual el turismo se vuelve una actividad planificada sectorialmente, con mecanismos formales para su ejecución y coordinación sectorial. Los objetivos de ese Plan Nacional de Turismo se dirigen más al carácter social del fenómeno -pero sólo en el discurso-como satisfactor del derecho al descanso de todos los habitantes del país, que a una función meramente económica -lo cual era cierto en la práctica- ya que se le asignaba un papel estratégico en la consolidación del desarrollo de México (Sectur, 1980).

Es menester indicar que la vigencia del plan fue de sólo dos años, ya que en mayo de 1983 se promulgó uno nuevo, el Plan Nacional de Desarrollo con vigencia de cinco años y en el que se vuelve a concebir al turismo en los términos antes planteados, aunque aquí destaca su papel estratégico en el 
desarrollo de México como esencia de la planificación sectorial, al asignarle al turismo un papel de captador de divisas y generador de empleos; se insiste en buscar la óptima eficiencia.

Durante los años 1982-1988, hay un periodo de transición en la política económica y social de México, que busca insertar al país en el concierto modernizador de las economías mundiales tratando de dejar atrás el esquema paternalista, la economía cerrada y proteccionista para adentrarse a una renovación en todos los ámbitos de la vida social y productiva en una era caracterizada por el interés privatizador, el neoliberalismo y la llamada reconversión industrial. Sin embargo, este periodo, que presidió Miguel de la Madrid Hurtado, registró los momentos más graves de la economía nacional con una inflación en más de tres dígitos, pérdida del poder adquisitivo de la mayoría de la población y la más grave crisis estructural de la época contemporánea.

De manera sintética, se puede señalar que el plan mencionado se regía por los principios del nacionalismo, la libertad y la justicia, la democracia como sistema de vida, la economía mixta, la rectoría del Estado y las libertades económicas, las libertades individuales, los derechos sociales y el internacionalismo (Poder Ejecutivo Federal, 1983). Con base en estos principios se definieron las orientaciones de gobierno a fin de obtener el consenso general, guiar el desarrollo del país y convertirse en mandato democrático.

En cuanto a la política sectorial, manifiesta en el llamado Programa Nacional de Turismo 1984-1988, se concibió al turismo como una actividad económica prioritaria en el proceso de planeación del desarrollo económico porque: "contribuye a la obtención de divisas, a la creación de empleos, al desarrollo regional y al estímulo de los demás sectores económicos, coadyuvando a la superación de la crisis que afectaba al país" (Sectur, 1985). Este fue un programa que rescató la importancia del turismo social asociado con el derecho al trabajo, el descanso recreativo, la difusión de los valores de México y reforzador de la identidad nacional; su planteamiento era coherente con los objetivos, estrategias y líneas de acción del Plan Nacional de Desarrollo. Se observa un intento de enfoque integral de control, regulación y coordinación del turismo bajo un estricto proceso de planificación e instrumentación de acciones.

A partir de 1988 se da un proceso de modernización que irradia a todos los sectores, entre ellos el turístico. Salinas de Gortari fue el artífice ideológico de esta nueva modernización que imponía la globalización y el neoliberalismo. 
El Programa Nacional de Modernización del Turismo 199|-1994, entre sus diversos objetivos, coincidía en propiciar que las empresas del sector, públicas, privadas y sociales, se desempeñaran con eficiencia y competitividad en los mercados nacionales e internacionales, conformando una nueva cultura empresarial turística que enfrentara responsablemente el reto que la modernidad imponía al desarrollo comunitario en aquel entonces. El desarrollo sostenido de la actividad turística requería de la participación creciente de los sectores privado y social, de la modernización de las empresas del sector y de que éstas se incorporaran efectivamente al desarrollo económico y social de las regiones en donde operaran.

En cuanto al Programa de Desarrollo del Sector Turismo 1995-2000, indicaba que la actividad turística era la opción más rápida y viable de desarrollo para algunas regiones del país; que el empleo turístico es de generación rápida, cuesta menos, incorpora fuerza de trabajo; que el país tiene ventajas relativas extraordinarias por su vecindad con grandes mercados y, sobre todo, por la singularidad de sus recursos. El plan tenía como objeto primordial fortalecer la competitividad y sustentabilidad de los productos turísticos de México para coadyuvar en la creación de empleo, la captación de divisas y el fomento al desarrollo regional, en el marco de la modernización, aumentando la capacidad competitiva del sector, promoviendo un desarrollo turístico sustentable, manteniendo, mejorando y ampliando la planta de empleo en el sector turístico, incrementando la captación de divisas por recepción de turismo y fomentando el desarrollo regional.

Respecto al Programa Nacional de Turismo 200 I-2006, su elaboración se llevó a cabo después de una consulta de participación ciudadana -siguiendo la tradición de la planeación democrática- en la que destacó la intervención de los empresarios del sector turismo, autoridades estatales y municipales, de organizaciones no gubernamentales, entre otros actores.

Este documento -el más actual en materia de política turística mexicanaplasma propósitos y aspiraciones de la política turística nacional; según indica, no permanecerá estático sino que tendrá un perfil vivo, para adecuarlo a la cambiante dinámica de la actividad.

En su presentación se indica que el programa fue elaborado luego de reuniones regionales con titulares de turismo de las entidades federativas, directivos del Consejo Nacional Empresarial Turístico, con la Asociación de 
Inversionistas en Hoteles y Empresas Turísticas, colegios y asociaciones de profesionales de turismo, académicos y expertos en la actividad, e instituciones vinculadas con la educación turística.

Los cuatro ejes de la política turística, por todos conocidos, son:

I) El turismo prioridad nacional

2) Turistas totalmente satisfechos

3) Destinos sustentables

4) Empresas competitivas

Como se puede apreciar, persiste la visión de la modernización pero con un matiz refuncionalizado a las necesidades del entorno globalizante y neoliberal.

\section{La estrategia modernizadora del turismo: el fomento de los cIP}

Desde hace más de treinta años el Estado ha fomentado el turismo con el fin de impulsar su desarrollo socioeconómico y la modernización del sector. La creación de los grandes centros turísticos, megaproyectos y centros integralmente planificados (CIP), fue vista como un instrumento idóneo para aprovechar los recursos, "inútiles" de otro modo; por ejemplo, el clima, el paisaje, la cultura y las tradiciones. Debido a la falta de capital, infraestructura, experiencia empresarial, entre otros, las instituciones gubernamentales impulsaron grandes obras públicas y otras medidas complementarias para atraer inversiones extranjeras y nacionales, sin embargo, agravaron el cuello de botella. Desde el punto de vista de los diferentes gobiernos mexicanos, aquellos megaproyectos traerían consigo la modernización de áreas rurales mediante su inserción en el mercado turístico nacional e internacional. En particular, se partió de la idea del efecto multiplicador, hecho que provocaría la creación de empleos y el aumento de ingresos así como el estímulo de otros sectores económicos ubicados en el ámbito rural, lo que permitiría un mejoramiento notable de las condiciones de vida de la población marginada.

Esta posición modernizadora y desarrollista fue cuestionada desde el principio. Se argumentaba que el supuesto desarrollo iría acompañado de serias deficiencias relacionadas con la urbanización turística -sin antecedentes e impuesta por actores ajenos a la región-, como la sobreexplotación de los recursos naturales, la migración no controlada, la formación de asentamientos 
irregulares, la marginación de la población autóctona, la pérdida de la autonomía política, económica y cultural, delincuencia y prostitución, entre otras. Cabe mencionar que la discusión académica y política sobre las consecuencias de esta intervención ha sido muy controvertida y aún no ha terminado.

Ante esta situación, el Estado asumió varias medidas -a partir de los años ochenta- para mitigar los impactos no deseables del turismo, pero sin cambiar sustancialmente el tradicional esquema desarrollista centralista. Según las fuentes oficiales (Sectur 200I), hoy en día se persigue un "desarrollo sustentable" que tome en cuenta, más que en el pasado, los intereses y las necesidades de la población residente, es decir, de los lugareños y los migrantes. Empero, esto sigue siendo mero discurso, ahí están los ejemplos y resultados de los habitantes de diversos centros turísticos que se sienten desplazados de sus antiguos recursos y medios de subsistencia por el advenimiento de segmentos especializados de turismo.

Los cinco megaproyectos diseñados: Cancún (I970), Ixtapa-Zihuatanejo (1972), Los Cabos (1974), Loreto (1975) y finalmente, Bahías de Huatulco ( 1984), empezaron a "redituar" hacia la década de los noventa, pero el beneficio no fue para aquellas áreas marginadas sino para el gran capital. El apoyo a la actividad turística en México se fortaleció a medida que el país dio juego a la inversión extranjera. Prueba de ello, fueron las actividades de inversión que la compañía hotelera norteamericana Stouffel llevó a cabo con sus asociados -los Hoteles Presidente de México- con una participación de 20 millones de dólares hacia 1991, operación verdaderamente elogiosa si se toma en cuenta el momento de crisis internacional. Con esa inversión se hubieran podido reacondicionar más de 40 hoteles pequeños y medianos en diversos destinos turísticos del país para mejorar su calidad y servicio.

En el caso anterior, la compañía norteamericana, con su oficina matriz en Clevelan, Ohio, formalizó la aportación del capital para Hoteles Presidente de México, que la convirtieron en socia mayoritaria de la operadora con acciones de los hoteles. En sí, se argumentaba que se buscaba consolidar a la empresa hotelera mexicana como una organización internacional de hoteles jóvenes y dinámicos, para coadyuvar al fortalecimiento de las actividades turísticas en México, con el apoyo de la iniciativa privada trasnacional del país (Turistampa, 1991: I-5).

Por otro lado, se vio que 199I fue un año con muchas posibilidades para el turismo por el Tratado de Libre Comercio con Canadá, Estados Unidos y 
México. Se tuvieron vuelos directos por parte de la línea aérea Canadian Airlines entre México, Toronto y Canadá; esta última se consideró el punto principal de negocios, con lo cual los agentes de viajes mexicanos diseñaron diversos productos de Canadá, ofrecieron sus programas, escenarios naturales, así como sus ciudades. Resultado del Tratado, la embajada canadiense informaba que los beneficios para aquella ciudad habían sido muy importantes, por lo cual se intensificarían las negociaciones con los agentes de viajes mexicanos.

A medida que se puso mayor interés a la actividad turística por parte del gobierno, fueron más los inversionistas privados extranjeros que quisieron invertir en México y aumentó la planta turística en diferentes sitios del país. La inversión pública y privada fortaleció las zonas turísticas y el turismo extranjero, principalmente por el incremento económico que redituó a los inversionistas, mientras el Estado controló la política económica turística bajo el auspicio del Tratado Trilateral del Libre Comercio, apoyado por los inversionistas nacionales y extranjeros que participaron activamente en este convenio.

En aquel entonces, los centros de recreo y descanso se construyeron en torno de lo que fue la mayor marina de México: la Marina Vallarta. Un proyecto de 150 embarcaderos de yates que incluyó un centro comercial de 210 tiendas, un parque de oficinas, casas de condominios y departamentos (Turistampa, 1992:3). Situr, filial del grupo Sidek Situr, elaboró un complejo de 160 hectáreas en Ixtapa-Zihuatanejo, destinados a construir cinco lujosas propiedades de recreo. Con el tiempo, Sidek construyó por lo menos una docena de marinas en el Pacífico, en el Golfo de México y a lo largo de la costa caribeña del país.

El grupo Sidek, importante fuerza en la elaboración y fabricación de metales, era también propietario de Hoteles Fiesta Americana en Puerto Vallarta, la Ciudad de México y Cancún, además de su propia cadena con seis centros de recreo, Plaza las Glorias. La organización adquirió luego el hotel Hyatt Continental de Acapulco, que después de una considerable renovación funcionó como Continental Plaza; el primero de una cadena de lujosos hoteles a la orilla del mar. El turismo, para aquel entonces, ya constituía las dos terceras partes de los negocios de Sidek y aunque siguió inaugurando nuevos hoteles de la Filial Situr se concentró además en la construcción de las marinas. "Solo en California hay 250000 dueños de lanchas" (Turistampa, 1992: 3), con este dato mercadológico era explicable que el grupo turístico constructor se abocara a ese tipo de proyectos. La estimación era construir más, a fin de que se 
pudiera contar con más lugares para lanchas. En ese momento se contaba con atracaderos permanentes en Marinas Vallarta, que pudieron dar acomodo a 450 naves, pero después de cinco años la capacidad se duplicó. Ello colocó a Puerto Vallarta como un lugar ideal para el turismo extranjero o viajeros nacionales acaudalados, que cuando no estaban navegando, muchos de ellos se alojaban en los centros de recreo. La existencia de marinas abrió además la posibilidad de fletar embarcaciones de placer, con tripulación o sin ella, para cruceros a lo largo de la costa mexicana.

"Estamos muy metidos en megaproyectos" decía Prysor Jones (Turistampa, 1992: 6), directivo de Sidek, ya que al mismo tiempo que en Puerto Vallarta e Ixtapa, se tenían planes para participar en desarrollos de Acapulco, Mazatlán, Baja California Norte y el Caribe mexicano. Los megaproyectos, según los concebía el Fondo Nacional de Fomento al Turismo (Fonatur), comprendían el desarrollo de instalaciones hoteleras, condominios, campos de golf, marinas y proyectos similares en zonas en las que existía infraestructura básica: carreteras, aeropuertos, luz, agua, energía y alcantarillado, como estímulo a la inversión extranjera.

Se dio aliento a los megaproyectos porque se tenía la seguridad de que en los siguientes años ya no se iban a necesitar más zonas de recreo y descanso, construidas a partir de cero como Cancún, Ixtapa y Huatulco. Un aspecto importante, en el manejo del turismo por parte del Estado, fue la difusión que realizó la Secretaría de Turismo. En su idea desarrollista, modernizante y respetuosa de los valores autóctonos: la federación proporcionaba millones de dólares para que la Secretaría de Turismo hiciera intensas campañas para animar a la prensa a fomentar los viajes a México, visitar sus ciudades coloniales y zonas arqueológicas con una mentalidad de cuidado a la herencia arqueológica e histórica de la nación. Nada más ramplón que eso, cuando el tipo de turismo que interesaba y se estaba captando era el procedente del sur de los Estados Unidos, que lo único que le interesaba era la diversión estrepitosa.

Para llevar a cabo la modernización del sector turístico, se efectuaron enajenaciones, se ejecutaron proyectos de infraestructura y urbanización, se comercializaron, administraron y arrendaron inmuebles, acciones que se consideraron con los sectores públicos y privados de cada localidad, siendo el Fondo responsable de su operación y mantenimiento, así como de su vigilancia y control, a fin de que se diera un “desarrollo armónico" en lo social, económico, 
urbano y ecológico, en los renglones de influencia en cada polo de desarrollo. Empero, la realidad mostraba otras situaciones de impacto negativo, sobre todo, en las poblaciones locales.

Hoy, nuestra modernización turística aboga por la competitividad, la calidad y la sustentabilidad. Sin embargo, un discurso tan demagógico sólo hace pensar en eso, cuando la realidad muestra que los beneficios no están llegando a quienes debieran.

\section{Algunos hechos actuales de la política turística mexicana}

Por actual entendemos un momento que entrelaza un pasado inmediato, el presente actuable y la tendencia próxima de coagular hechos, ideas y acciones. No se olvide que tenemos un Programa Nacional de Turismo que abarca desde el 200 I hasta el 2006, el cual sigue vigente y considera el criterio esbozado. Más aún, tenemos un documento denominado: El turismo mexicano en el largo plazo. La perspectiva 2020, editado por la Sectur en octubre del 2000, donde la visión de la política es hacer del turismo una prioridad. En palabras llanas se podría decir: hacer más pero con lo mismo, pues el modelo de desarrollo turístico no ha cambiado, sólo se ha perfeccionado. Obsérvese la siguiente declaración de John McCarthy quien señalaba -a propósito de la clausura formal de los trabajos del II Foro Nacional de Turismo y Medios de Comunicación:

De acuerdo con un estudio de la OMT, México llegará a captar 50 millones de turistas en el año 2020, que le catapultarán al octavo sitio a escala mundial, a partir del décimo que hoy ostenta (sic). A pesar de que están entrando nuevos competidores al sector turístico, la OMT confía en México y creemos que por algo será [La Jornada, 2005b: 24].

Incluso el documento titulado: Dónde estamos y hacia dónde vamos (Sectur, 2006), en el acetato número cuatro, se muestra cómo México ha avanzado cinco lugares en medio siglo, ubicándose en el octavo lugar, algo nada especial o grandioso como para jactarse, sobre todo si al analizar el cuadro se observa el avance que ha tenido China, o en un periodo similar en el que ni figuraba $y$, actualmente, en las posiciones del ranking mundial del turismo se le ubica en cuarto lugar; ello nos permite notar que en México en realidad no ha habido avance ni cambios significativos. 
Considerando como cierto lo anterior, dada la tendencia que México ha mostrado en el ranking mundial (ОTM, 200I), si se analiza, por ejemplo, el comportamiento de la década pasada, México conservó su octavo lugar en el ranking mundial, y pasar de 17.1 millones de turistas internacionales en 1990 a poco más de 20.6 millones en el 2000 , le representó crecer a una tasa anual promedio de $1.6 \%$, una de las tasas de crecimiento más bajas de ese grupo de países. Lo dramático del caso es que su participación en el mercado disminuyó considerablemente, pues de tener 3.7\% del mercado mundial en 1990, en el 2000 sólo alcanzó $3.0 \%$. Si tan sólo para el 2000 hubiera mantenido su cuota de mercado en $3.76 \%$ hubiera recibido cerca de 26.3 millones de turistas, es decir, más de seis millones. En el caso de China, es digno de destacar que en ese periodo - 1990-2000- pasó del décimo segundo lugar al quinto. Se dice fácil, pero este movimiento representó más de $\mathbf{2 0 . 7}$ millones de turistas internacionales para ese país. ¡Casi 2.I millones más de turistas internacionales cada año!

Otro caso es el de Polonia, que avanzó del lugar 27 en 1990 con una afluencia de 3.4 millones de turistas, al lugar 12 en el 2000, con 17.4 millones. En sólo diez años, 14 millones de visitantes más. Alrededor de 1.4 millones más cada año. En comparación con el crecimiento de México, estos dos países han avanzado significativamente. China ha rebasado a México por concepto de llegadas y de ingresos.

Los datos anteriores nos obligan a cuestionar la posición de México y a pensar si somos realmente competitivos a pesar de estar en la élite de los I5 países más importantes en el ranking mundial. Igualmente, si el tipo de política o políticas -pues son varias bajo un mismo matiz-son las más adecuadas; si el modelo de desarrollo turístico puede seguir funcionando con remiendos a la cuestión financiera, de inversión, fiscal, de supuesta competitividad e innovación que irradia a todos los actores con programas de capacitación y promoción obsoletos, o si se requiere reconvertirlo destacando el papel de la micro y pequeña empresa y del desarrollo interno.

En entrevista concedida a Víctor Trujillo, Rodolfo Elizondo señalaba que en México no se tiene una política turística clara y definida, por lo cual estaba preparando un documento ex profeso (Trujillo, 2005). En enero de 2005, Elizondo volvió a señalar respecto del turismo: “...ya basta de la política de simulación...” en referencia al caso específico de los casinos (La Jornada, 2005a: 4). Esta declaración contrasta fuertemente con el documento Dónde estamos y hacia dónde vamos, en el cual se indica, en el acetato dos, punto III, que "México 
está elevando el turismo hacia una política de Estado, aprovechando sus ventajas competitivas para fortalecer la economía, preservar el patrimonio y distribuir mejor la riqueza entre todos los mexicanos". Qué ironía, pues esta "política de Estado" hoy sólo se ha refuncionalizado en beneficio de las grandes empresas y el gran capital.

Baste un ejemplo. Durante el panel de expertos, en octubre de 2004, presentados por la presidenta del Meeting Professionals International (MPI), Yarla Covarrubias, se reunieron Elizabeth Yáñez Robles, diputada federal e integrante de la Comisión de Turismo del Congreso; Luis Soto, columnista del periódico El Financiero; Crispín Barrera, conductor de Mundo Ejecutivo TV, y Gordon F. Viberg, presidente del Consejo Nacional Empresarial Turístico (CNET), para abordar el tema "Cómo afecta en México la política en turismo de negocios”. En esa reunión,Viberg señaló que:“...para que se incremente el número de grandes eventos es necesario que haya estabilidad jurídica, política y económica, ya que en este momento, el país sólo goza de esta última" (Villagrán y Pacheco, 2004; cfr. Boletín Informativo, 2004). En otra nota, Rafael Suárez Vázquez señala que en el cuarto informe de Gobierno el turismo no tuvo la prioridad que se arguye (Suárez, 2004) y, por lo que se leyó del quinto Informe la situación no cambió mucho. Entonces, ¿de qué política se está hablando?

\section{Neoliberalismo, globalización y modernización de la política turística}

En las dos últimas décadas del siglo $\mathrm{XX}$, el mundo entero ha vivido bajo el dominio cada vez mayor de una política y una ideología a las que sus partidarios y promotores bautizaron con el nombre de neoliberalismo. Los estragos que esa política y esa ideología han causado entre los pobres más pobres -y aun en las clases medias- son hoy reconocidos hasta por los ricos y más ricos, sus indudables beneficiarios. Pero aunque muchos de éstos conozcan los estragos y hasta anuncien otros mayores, se las ingenian para seguir aplicando exactamente la misma política neoliberal al tiempo que reniegan de su nombre o se le cambian, o dicen que van a aplicar una política distinta y "humanitaria", o un "neoliberalismo social" o una "tercera vía". En cualquier caso sostienen, sin la menor base científica, que los efectos adversos del neoliberalismo son provisionales y corresponden a medidas calculadas que a la larga van a resolver los problemas de las mayorías empobrecidas. 
Los neoliberales o liberales en economía son esencialmente partidarios del sistema capitalista, y como tales saben a la perfección que el capitalismo actual se encuentra excesivamente concentrado. El problema no es la intervención del Estado como lo quieren hacer ver los neoliberales, es más bien al revés: las grandes empresas se han superpuesto al Estado utilizándolo como instrumento para sus fines económicos. Esto no sucede solamente en las naciones subdesarrolladas sino que alcanza su mayor expresión y significado en las altamente industrializadas. El ejemplo más elocuente, el caso de Estados Unidos, modelo por antonomasia del liberalismo económico, con su complejo industrial militar, que ilustra ampliamente cómo las empresas se sirven del Estado para dictar no sólo la política económica que deben de adoptar, sino la política exterior.

Estos hechos dan la razón a Marx cuando caracterizaba al Estado moderno como un instrumento de dominación de una clase sobre otra, y que no es más que una junta que administra los negocios de toda la burguesía (Marx, 1985).

Las contradicciones del neoliberalismo o liberalismo económico son las mismas que las del sistema capitalista. Hoy día estamos en presencia de una ofensiva del neoliberalismo en todo el mundo; aplicando a tambor batiente sus postulados exige que el Estado sea apenas un observador de los quehaceres económicos y que la libre empresa, o la iniciativa privada, sea la que regule el mercado.

El neoliberalismo, como nueva política del capitalismo corporativo, ha diseñado una globalización funcional a sus intereses cuyos efectos laterales no sólo han aumentado la pobreza y la extrema pobreza, sino la explotación de los trabajadores, la transferencia de excedentes de los países periféricos a los centrales y de los negocios no organizados a los negocios organizados.A principios del siglo XXI las fuerzas dominantes se han propuesto globalizar más, desregular más, flexibilizar más; mucho más de lo que habían globalizado, desregulado y flexibilizado al mundo hasta entonces, con mayor profundidad y ventaja.

En este sentido, la globalización se ha convertido en un referente de las relaciones internacionales contemporáneas, pero también se vincula a fenómenos diversos de las sociedades nacionales; la globalización es en realidad un proceso que desdibuja fronteras en lo interno y en lo externo e induce a un nuevo tipo de vinculación que articula multifacéticamente estos dos ámbitos.

En la acepción más común que se le da al término, la globalización describe la creciente interdependencia e integración que se produce entre los pueblos a raíz de las facilidades tecnológicas que existen para que las ideas, imágenes, 
productos y dinero fluyan a través de las fronteras. Esta mayor asiduidad en las interconexiones conduce a una creciente interdependencia y homogeneidad y dispone a los distintos actores nacionales e internacionales hacia una mayor cooperación e interdependencia.

La globalización es, en realidad, un tiempo presente que nos hace sentir la necesidad de vivir la urgencia y la prontitud de las cosas. Antes, el mundo se estructuraba en torno al tiempo de la política, lo que implicaba constantes referencias al pasado para el manejo del presente y mantenía el objetivo de proyección hacia el futuro; con los cambios tecnológicos, comunicacionales y económicos de las últimas décadas, se ha comenzado a producir una gran transformación cultural que ha desplazado el tiempo de la política por el tiempo de la economía globalizante, la cuestión del mercado, la velocidad del consumo, de la producción y los beneficios desvinculados del pasado, que transforma todo en presente e involucra los anhelos futuros en inmediatez.

Así, la economía mundial ha dejado de ser el resultado de la suma de las economías nacionales que funcionaban de acuerdo con sus propias leyes y se relacionaban a través del comercio. Ahora, estas economías nacionales se convierten en partes integrantes de una espacialidad económica a nivel planetario. Con ello se da pie a entender que la globalización se inscribe en una continuidad del desarrollo del capitalismo y le restituye a éste su vocación natural que ha sido más transnacional que internacional, que se libera de las relaciones de fuerzas entre los Estados, que se desvincula de las relaciones sociales para reestructurarlas y que liberaliza y universaliza el mercado.

La globalización comprende algo más que la simple actividad por fuera de las fronteras y el control de los Estados.Algunos autores consideran que sólo se puede hablar de globalización cuando las actividades en realidad tienen lugar en una arena que es más o menos global, cuando los trabajos se organizan, planean o coordinan en una escala global y cuando las acciones entrañan cierto grado de reciprocidad e interdependencia, como actividades localizadas y situadas en diferentes partes del planeta (Thompson, 1995: I50).

El fenómeno de la globalización está generando polos exitosos de acumulación con empresas que tienen elevadas tasas de crecimiento y rentabilidad y que funcionan según estrictas normas internacionales para el flujo de productos, tecnología, capitales e información; lo que está dando lugar a ello es el surgimiento de redes transnacionales de poder, centralizando las funciones de coordinación en nichos urbanos globalizados. 
Podemos concluir, entonces, que la globalización como "proceso" avanzado dista mucho de ser una realidad, mientras que la economía se está mundializando sobre una base fundamentalmente internacional que reproduce su articulación en torno a núcleos de acumulación y crecimiento micro regionales que pueden ser ciudades, regiones o metrópolis.

En este sentido, hablar de las políticas públicas de lo turístico no nos lleva así, sin más, a la descripción de las acciones y programas más importantes que en materia de modernización se han efectuado hasta el momento; antes bien nos conduce a reflexionar que en la conformación de los compromisos políticos continuamente estamos en la recomposición del todo social. De ahí que la política turística no es la simple acción y ciertos programas donde el Estado busca el "bien común" para todos los actores involucrados; el elemento estamental es la existencia ilusoria de los asuntos del Estado como asuntos del pueblo, tal ilusión, de que los asuntos generales son asuntos públicos, es la ilusión política de la sociedad civil. La síntesis del Estado político es la síntesis de la propiedad privada; para el Estado en cuanto asunto real, sus asuntos generales del mismo son asuntos públicos (Habermas, 1989). En el ámbito de lo público la política se vincula, entonces, al poder público, a la ley como derecho e interés público, es decir, al Estado político, aunque no la agota ahí.

Bajo esta lógica, la formación económico social es un proceso concreto de la totalidad social que incorpora la base productiva o tejido económico y las relaciones que se derivan de ella, que pueden convivir y articular formas diversas y contradictorias, siendo una de ellas la dominante. Así, el mundo del trabajo y su organización, al igual que el mundo de la vida que incluye los valores y las relaciones intersubjetivas, está dominado por el dinero y el poder que se implanta por vía de la producción.

La formación social, entonces, está determinada por un principio de organización dado por las relaciones materiales o de producción, pero paradójicamente los principios de organización limitan la capacidad que una sociedad tiene de aprender sin perder su identidad. Las relaciones en una formación social se vinculan con el principio de organización, de lo cual se deduce el consecuente enfrentamiento entre individuos y grupos, cada vez más renovados con pretensiones e intenciones incompatibles. Esto se manifiesta en la sociedad de clases donde se traman los antagonismos tanto en las relaciones de producción como en las de distribución; mientras esas pretensiones e intenciones no lleguen a la conciencia de los participantes, el conflicto permanece latente 
y requiere de justificación ideológica que encubrirá la distribución asimétrica de las oportunidades de satisfacción legítima de las necesidades, manifiesta en una cierta política pública, en nuestro caso, la del turismo.

De esta manera, las políticas turísticas, insertas en este modo de producción capitalista al igual que toda la realidad, están sujetas a un proceso permanente de cambios y transformaciones. El capitalismo es una realidad compleja, funciona como una unidad de aspectos técnicos, sociales e ideológicos; al interior del mismo se establecen relaciones sociales de las cuales se construye cierta configuración de representaciones, valores, instituciones y formas de conciencia social que se plantean y formulan en políticas que aparentemente buscan modernizar un sector, por ejemplo. En este sentido, la política turística se vincula a los procesos de modernización.

Si los procesos de modernización tienen que ver con la reorganización del capital, del cual se gestan transformaciones en lo económico -sobre la base del cambio de las estrategias de acumulación-, pero también en lo social y político, conviene aclarar que el término modernización ha sido empleado comúnmente para referirse a un proceso de cambio social en el que las sociedades "menos desarrolladas" transitan para adquirir las características de las "desarrolladas". Esta concepción lo único que muestra es la unilateralidad del significado, ya que se restringe a la importancia que tiene o debe tener el desarrollo económico.

Al privilegiar el crecimiento económico y el progreso como elementos centrales que caracterizan a la modernización, se reduce y parcializa el concepto, pero además se difumina la diferencia entre modernización y modernidad. Si la modernización fragmenta a la modernidad, desde su concepción originaria, y la convierte en un simple patrón de procesos evolutivos sociales neutralizados en tiempo y espacio; si la modernización es un mero proceso histórico de racionalización y únicamente presenta estructuras sociales determinadas por la diferenciación de la empresa capitalista y el aparato estatal burocrático; $y$, si la modernización es un conjunto de procesos que se refuerzan mutuamente, desde la formación de capital y la movilización de recursos hasta la implantación de poderes políticos centralizados y el desarrollo de identidades nacionales, entonces la modernización no es un proceso de racionalización social sino mera instrumentalidad.A la manera de Habermas la modernización es “....desde arriba, anclaje motivacional y encarnación de estructuras de conciencia y, desde abajo, resolución innovadora de los conflictos de intereses que resultan de los 
problemas de la reproducción económica y de la lucha por el poder político, necesaria para la institucionalización de la acción racional con arreglo a fines" (Habermas, 1989: 286).

Entender a la modernización como un proceso de racionalidad implica reconocer que aquella se produce en la racionalidad cultural, seguida por la racionalidad social como una progresiva racionalización de las imágenes del mundo, lo que supone un proceso de aprendizaje que fomenta un patrón de racionalización a consecuencia de la cual la racionalidad instrumental penetra a través de la economía y del Estado en otros ámbitos de la vida y allí adquiere su supremacía (Habermas, 1989: 305).

Se puede observar, entonces, que la política turística de modernización implica un modelo que coloniza e impone un proceso selectivo de racionalización que privilegia la instrumentalidad del sistema y se proyecta hacia el mundo de la vida. Así, la modernización -como racionalidad instrumental- significa perfeccionamiento de la sociedad con base en el progreso de las técnicas y los medios de producción, de la circulación y consumo, de la organización social y gestión pública; es decir, es una reorganización de la vida social en su totalidad.

\section{Conclusiones}

El devenir de la política turística, en el esquema de la modernización, siempre ha buscado alcanzar los objetivos del desarrollo y el progreso. La situación se vuelve compleja cuando el término adquiere un nuevo sentido a la luz de la globalización y el neoliberalismo. Como se observa, hablar de modernización, neoliberalismo y globalización de la política turística es reconocer elementos de disolución del Estado moderno actual. Y es que el mercado está sustituyendo el quehacer político, apoyado por el discurso del neoliberalismo. La creación de riqueza es un espejismo para los pobres, el paraíso de la libertad total es en realidad un espacio ficticio, un paraíso perdido. Esta economía mundialmente constituida está abriendo una brecha enorme entre los que tienen los medios y los que no los tienen, patentizado en el desarrollo tecnológico y el subdesarrollo social como políticas que modernizan.Aquí la interrogante es: ¿cómo combinar la unidad y la diversidad para superar esta moderna sociedad desigual, compasiva y en momentos utópica? El camino es reconfigurar los planos de la democracia, el poder y la política, y particularmente el papel del turismo en aquéllas. 


\section{FUENTES CONSULTADAS}

Aziz Nassif, Alberto (2003). "La ciencia política: empirismo, fortaleza vacía, hibridación y fragmentos”, soJ, Departamento de Estudios Sociopolíticos y Jurídicos, ITESO [en línea], [8 de junio de 2006] México. Disponible en: www.soj.iteso.mx/investigacion/ciencia_politica.html Beneyto, José María (1993). Apocalipsis de la modernidad. El decisionismo político de Donoso Cortés. Barcelona: Gedisa.

Boletín Informativo (2004). “Mensaje de la Presidenta”. Año 2, nùm. 16, octubre de 2004. Meeting Professionals Internacional (MPI) Capítulo México. Disponible en: http://www.mpimexico.org.mx/images/boletines/ boletin I6.html [2007, 5 de julio].

Boyer, Robert (1977). "Les mots et les réalités”, Mondialisation au-dela des mythes. París: La Découverte.

Cisneros, Isidro H. (2002). “Las raíces de la política absoluta o de la concepción del enemigo”. Cuadernos de Política. México:Departamento de Estudios Políticos. Universidad de Guadalajara / Gedisa.

De la Torre Padilla, Óscar ( 1982). El turismo: fenómeno social. México: Porrúa. Diario Oficial de la Federación (196I). Ley Federal de Turismo. México, D.F., 3 de enero de 196I.

García, Carlos (2004). “Organismos financieros internacionales”, Radio sin nombre [en línea]. [29 de marzo de 2004] México: Disponible en: http://espora.org/revueltas/article.php3?id_article=22.

García de Fuentes, Ana (1979). Cancún: turismo y subdesarrollo regional. México: UNAM. González Casanova, Pablo (1999) Algunos conceptos básicos. México: Siglo XXICEIICH-UNAM.

Guerrero Orozco, Omar (1986). Las ciencias de la administración en el Estado absolutista. México: Fontamara.

Habermas, Jürgen (1989). Teoría de la acción comunicativa. Buenos Aires:Taurus. Herrerías,Armando (1958).“Turismo: proyección integral, historia y actualidad”. IMIT. Documento inédito 989. México.

lanni, Octavio (1996). Teorías de la globalización. México: Siglo XXI.

Jiménez Martínez, Alfonso de Jesús (1992). Turismo, estructura y desarrollo. La estructura funcional del turismo internacional y la política turística de México. Desarrollo histórico. 1945-1990. México: McGraw-Hill.

La Jornada (2005a) "Casinos de México”, 2 de enero de 2005. 
(2005b) "México captará 50 millones de turistas en el 2020: ОMT", 2 de febrero de 2005.

MacDonald Escobedo, Eugenio (I98I). Turismo: una recapitulación. México: Bodoni. Marx, Carlos (1985). El capital. México: Fondo de Cultura Económica.

Molina, Sergio et al. ( 1985 ). Turismo alternativo. Un enfoque crítico y conceptual.

México: Nuevo Tiempo Libre.

Monfort Mir,Vicente M.(2000).“La política turística:una aproximación”. Cuadernos de Turismo núm. 6. Universidad de Jaume I. España.

Moreno Toscano, Octavio (1969). Turismo: una interpretación. Tesis de [idoctorado?] México: Colegio de México.

Novo Valencia, Gerardo (1977). Diccionario general de turismo. México: Diana.

Olivera Toro, Jorge (1970). Legislación y organización turística mexicana. México:

Porrúa.

OMT (2002). La política turística mundial. España: Organización Mundial de Turismo.

(200I). Tendencias de los mercados turísticos. Madrid: Organización Mundial de Turismo.

Ortiz, Renato (1996). La globalización de la cultura. Buenos Aires, Argentina: Alianza.

Ortuño Martínez, Manuel (1966). Introducción al estudio del turismo. México: Porrúa.

Poder Ejecutivo Federal (1983). Plan Nacional de Desarrollo I983-I988. México.

Quirós Pérez, Miguel y Gutiérrez Herrera, Lucino (1992). De Carranza a Salinas. Otras razones en el ejercicio del poder en México. UAM. Unidad Azcapotzalco. México: Casa Abierta al Tiempo.

Rodríguez Araujo, Octavio ( 1988 ). México: estabilidad y luchas por la democracia 1900-1982. México: CIDE-El Caballito.

Romero, Héctor Manuel (1977). Crónica mexicana del turismo, vols. I y II. México: UNAM (Textos Universitarios).

Secretaría de la Presidencia (1983). Plan Nacional de Desarrollo 1983-1988.

México: Gobierno de los Estados Unidos Mexicanos.

Sectur (2006). Dónde estamos y hacia dónde vamos. México: Secretaría de Turismo.

(200I). Programa Nacional de Turismo 200I-2006. México: Sectur. 
(1985). Programa Nacional de Turismo 1984- 1988. México: Sectur. (1980). Plan Nacional de Turismo. México. México: Sectur. SPP (1980). Plan Global de Desarrollo 1980-1982. México: Secretaría de Programación y Presupuesto.

Suárez Vázquez, Rafael (2004). “El turismo no mereció prioridad en el 4to. Informe de Gobierno". Periódico on Line, 3 de septiembre de 2004. Disponible en: http://revistabuenviaje.com/index.html [2004, 5 de septiembre]. Sunkel, Oswaldo y Paz, Pedro (1976). El subdesarrollo latinoamericano y la teoría del desarrollo. México: Siglo XXI.

Tello, Carlos (1983). La política económica en México. 1970-1976. México: Siglo XXI. Thompson, John B. (1995). The media and modernity. A social theory of the media. Polity Press. Cambridge.

Tocqueville,Alexis (1957). La democracia en América. México: Fondo de Cultura Económica.

Torruco Marqués, M. (1988). Historia institucional del turismo en México: 19261988. México:Asociación Nacional de Egresados de Turismo, A. C.

Trujillo,Víctor (2005). El cristal con que se mira. Entrevista a Rodolfo Elizondo, Secretario de Turismo. México: Noticieros Televisa. Canal 4, 23 de octubre de 2005.

Turistampa (1992). “Marina Vallarta”. Turistampa, núm. 5I2, vol. 25, año 22. México, 3-8.

(|99I). "Inversiones extranjeras en la industria turística mexicana". Turistampa, núm. 5 I I, vol. 25, año 22. México, I-5.

Villagrán, Alfredo y Pacheco, Marco Antonio (2004). "La política en el turismo de negocios en México". Miércoles 6 de octubre de 2004. Buen viaje on Line. Periódico electrónico. Disponible en: http://www. revistabuenviaje.com/b_travel/articulos/ariculogaston/articulos I.html [2004, 7 de octubre]. 